\title{
CLOUD GIS BASED WATERSHED MANAGEMENT
}

\author{
G. Bediroğlu ${ }^{\text {a, } * \text {, H. E. Colak }}{ }^{\mathrm{a}}$ \\ ${ }^{a}$ KTU, Dept. of Geomatic Engineering, Karadeniz Technical University, Trabzon, Turkey- (gamze.yilmaz@ktu.edu.tr, \\ ecolak@ktu.edu.tr,)
}

KEY WORDS: Watershed, GIS, Cloud GIS, Environmental Management

\begin{abstract}
:
In this study, we generated a Cloud GIS based watershed management system with using Cloud Computing architecture. Cloud GIS is used as SAAS (Software as a Service) and DAAS (Data as a Service). We applied GIS analysis on cloud in terms of testing SAAS and deployed GIS datasets on cloud in terms of DAAS. We used Hybrid cloud computing model in manner of using ready web based mapping services hosted on cloud (World Topology, Satellite Imageries). We uploaded to system after creating geodatabases including Hydrology (Rivers, Lakes), Soil Maps, Climate Maps, Rain Maps, Geology and Land Use. Watershed of study area has been determined on cloud using ready-hosted topology maps. After uploading all the datasets to systems, we have applied various GIS analysis and queries. Results shown that Cloud GIS technology brings velocity and efficiency for watershed management studies. Besides this, system can be easily implemented for similar land analysis and management studies.
\end{abstract}

\section{INTRODUCTION}

A watershed is an area of land and water bounded by a drainage divide within which the surface runoff collects and flows out of the watershed through a single outlet into a lager river or lake. The concept of watershed indicates a specific relation between the natural geographical substrate, the water, the built environment and the population. The watershed is therefore considered as the territorial unit of reference for urban hydrology (Romnée et al., 2015; Musy and Higy, 2009). Streams with urban watersheds are almost universally subject to degradation, largely driven by changes to flow and sediment inputs from the watershed (Russell et al., 2016). Watershed management approaches are evolving throughout the country and are being used to solve tough problems. (Url-1, 2017) The approach of watershed management ought to be holistic and integrated involving hydrological, biophysical and socioeconomic systems and peoples' participation, is recognised as a key factor in effective implementation of the programme. Thus, WSM is a combination of 'science and art'/'technology and philosophy' (Reddy et al., 2017 ; Reddy et al., 2010; Tiwari et al., 2008). WSM implies an effective conservation of soil and water resources for sustainable production. Predicting soil erosion potential is important in watershed management. Soil erosion risk varies from case to case, depending on topography of the watershed, soil characteristics, local climatic conditions, land use, and land management practices (Zare et al., 2017). Several conventional methods such as geological, hydrogeological, geophysical, and photogeological techniques were employed to delineate groundwater potential zones. However, recently, with the advent of powerful and high-speed computers, digital technique is used to integrate various conventional methods with satellite image/remote sensing (RS) techniques and geographical information system (GIS) technology (Pinto et al., 2017). One of the best efficient tool for determine watershed zones and analysis is using GIS with relevant spatial datasets. Desktop GIS has been already supporting watershed analysis and has been used in many various studies. But appliying these analysis on Cloud GIS exist in just a few study. A new era of geosciences has been occurred with the mix of CC and GIS, this is called Spatial Cloud Computing (SCC) or Cloud GIS (Bediroglu et al., 2014). GIS Cloud has been a suggestive approach to upgrade the conventional GIS applications in order to provide broad spectrum services to the users across the globe (Bhat et al., 2011). We consider using Cloud GIS will bring opportunity to determine watershed zones, generate a huge GIS dataset on cloud and apply GIS analysis, queries at watershed zone on cloud, easier and efficient. Results may be shared with participants easily and a discussing and decision system will be provided with internet portals.

\section{MATERIAL AND METHODS}

\subsection{Study area}

Study area is located along Ceviz river exists between Unye and Fatsa districts of Ordu city Turkey. At this study we investigated watersheds, effecting zones and possible effecting zones due to 4 dams. Study area is shown at Figure 1. 


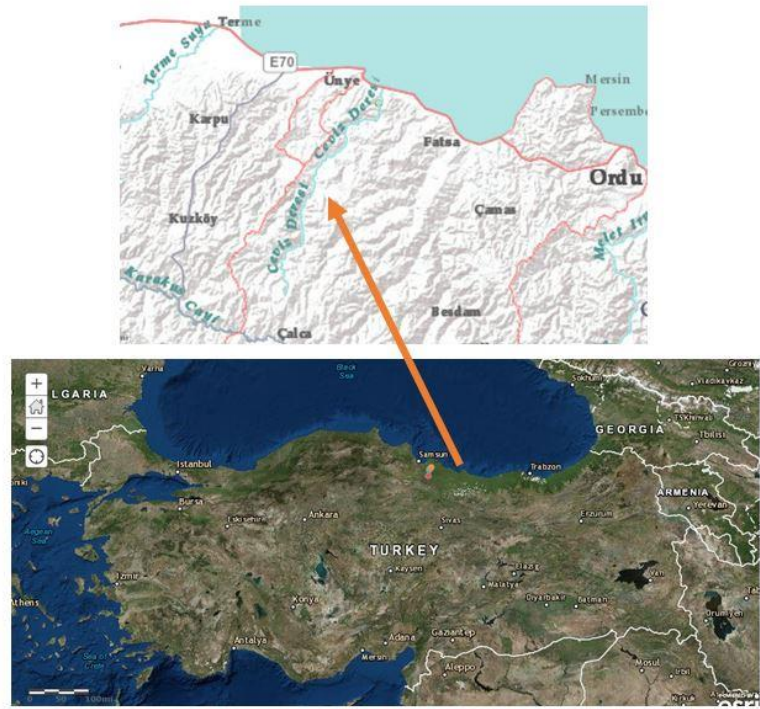

Figure 1: Study area

\subsubsection{Creating geodatabase and uploading to cloud}

After determining watershed zone we have prepared a geodatabase for the study area containing Hydrology data (Rivers, Lakes), Geology, Soil, Climate, Land Use) at ArcMap Desktop 10.5 software. We uploaded all he geodatabase to cloud and made them ready for queries and analysis. A view of geodatabase can be seen at Figure 3.

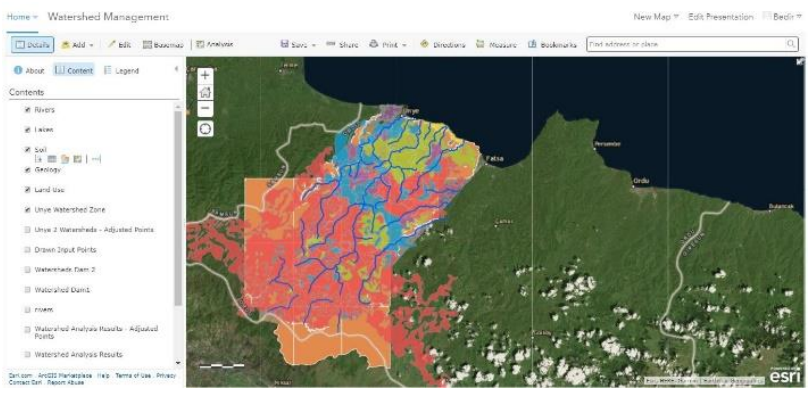

Figure 3: Geodatabase of watershed area on cloud

\subsection{Methodology}

At this study all the GIS analysis, queries and visualizations were made on Cloud GIS. Cloud based world topology hosted on cloud servers have been used for watershed analysis. Cloud based satellite imagery have been used for visual observation and tests. Hydrology data (Rivers, Lakes), Geology, Soil, Climate, Land Use) have been uploaded on cloud servers and final analysis have been applied. We used ESRI's cloud platform supporting GIS files (.shp) and other well-known spatial formats. All the GIS datasets have been ready in same format and save system for watershed management.

\subsection{Application}

\subsubsection{Watershed analysis}

Firstly, we have made watershed analysis for study area. Total watershed area zone is shown in Figure 2. This analysis is completely done with Cloud GIS technology. We took world topology from internet servers and applied analysis on cloud. Result map of watershed zone analysis is hosted on cloud after generation.

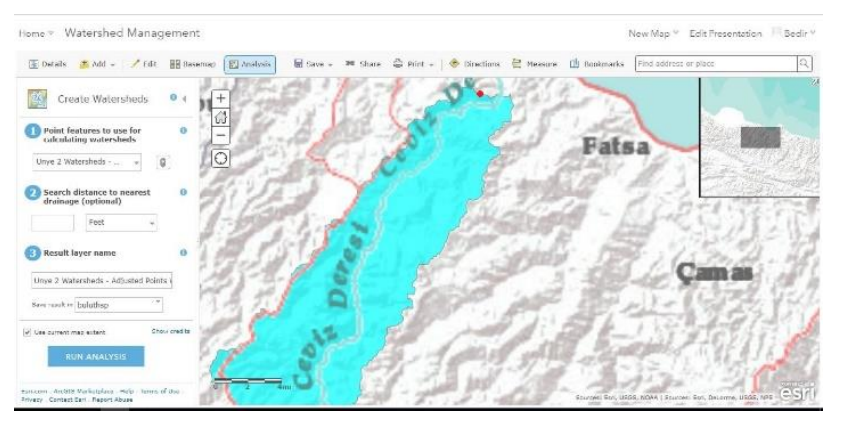

\subsubsection{GIS analysis on cloud}

At this part of study we investigated applying GIS analysis as creating density maps on cloud. Climate data containing average rainfall amounts surveyed on stations was used fir this purpose. We interpolated average values and created a continuous surface on cloud. GIS analysis screen can be seen at Figure 5.

Figure 2: First watershed analysis 


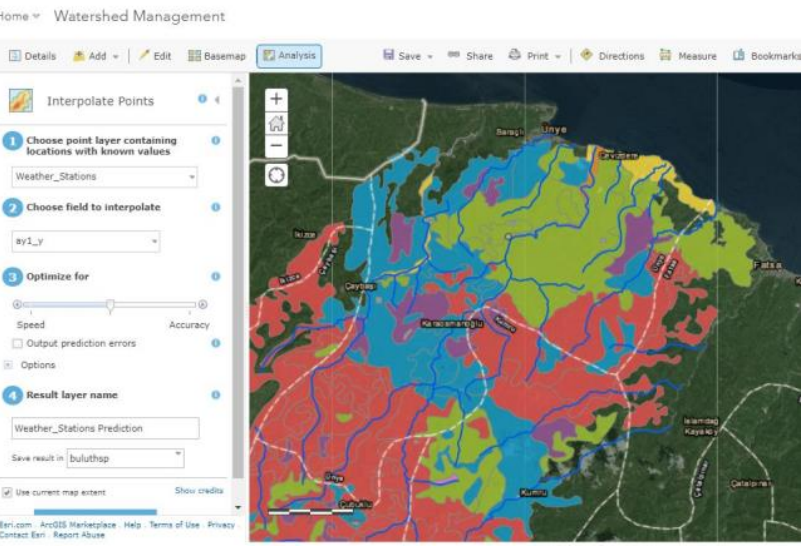

Figure 5: Applying GIS analysis for watershed management purposes on cloud

\subsubsection{Advantageous skills of Cloud GIS: Basemap functions}

Cloud GIS technology provides huge GIS and remote sensing basemaps hosted on cloud. This is a fast and impressive advantage according to us because system enables suddenly jumping from one base map to another. Satellite images, street maps, National geographic maps are ready for usage (Figure 6). Besides this shared huge GIS datasets created by other cloud users are accessible for users of system.

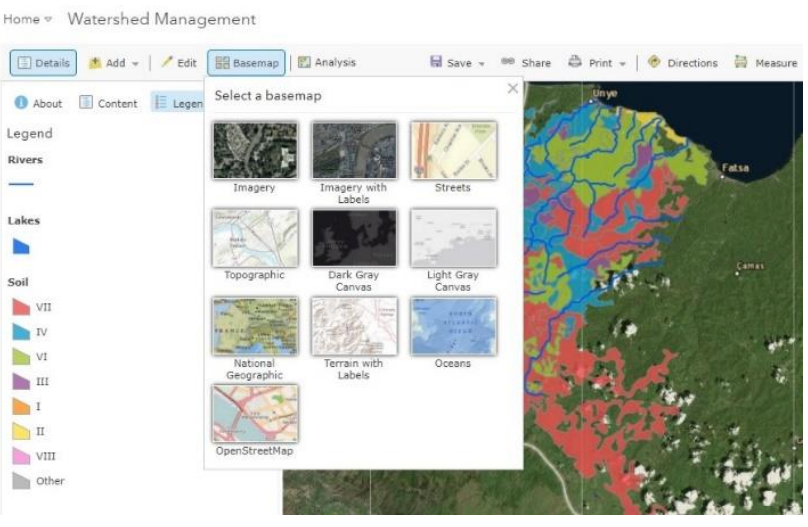

Figure 6: Basemap changing function of cloud systems

\section{RESULTS \& CONCLUSIONS}

Watershed management approach is crucial approach for managing lands, saving environment and habitat. This study purposes to enable watershed management with cloud GIS based approach. Pre studies shown that working on cloud brings velocity and efficiency for GIS studies. First, we can get a huge set of cloud hosted GIS and Remote sensing database. Cloud based GIS layers are World topology, World hydrology etc. also cloud based remote sensing data are various satellite views, infrared band views, new and old imageries. Getting ready datasets brings velocity for projects besides this; we uploaded our own GIS datasets for working in Hybrid cloud model. Other side, tested GIS analyses and queries gave efficient results. In terms of accuracy, there is no difference between Desktop and Cloud GIS when they are compared. This working model also enables easily data share between participants of project (Government staff, public sector, university staff and field workers). All the system is accessible with Internet browsers or mobile phones if sharing and discussing is relevant. Permissions on geodatabase can be identified according to user such as full access (view, download, change data) or limited access (just view). In future studies this study will be enriched with environmental care purposes such as protecting, generating fish habitats and other ecosystems.

\section{REFERENCES}

Bhat M.A., Shah R.M. and Ahmad B. 2011. Cloud Computing: A solution to Geographical Information Systems (GIS). International Journal on Computer Science and Engineering (IJCSE). Pages: 594-600

Bediroglu, S., Yıldırım, V. and Erbaş, Y.Ș., 2014. Application of GIS Analyzes with Cloud Computing. FIG Congress 2014 Engaging the Challenges - Enhancing the Relevance Kuala Lumpur, Malaysia 16-21 June 2014.

Pinto, D., S. Shrestha, M. S. Babel and S. Ninsawat. 2017 "Delineation of groundwater potential zones in the Comoro watershed, Timor Leste using GIS, remote sensing and analytic hierarchy process (AHP) technique." Applied Water Science 7(1): 503-519.

Musy, A. and Higy, C., 2009. Hydrologie: Une science de la natüre. Ingénierie de l'Environnement, PPUR, 306 p.

Reddy, V.R., Reddy, G. and Soussan, J., 2010. Political Economy of Watershed Management: Policies. Institutions, Implementation and Livelihoods, Rawat Publishers, Jaipur.

Reddy, V.R., Saharat, Y.S. and George, B., 2017. Watershed management in South Asia: A synoptic review. Journal of Hydrology, Volume 551, 2017, Pages 4-13, ISSN 0022-1694.

Russell, K.L., Vietz, G.J. and Fletcher, T.D., 2016. Global sediment yields from urban and urbanizing watersheds. EarthSciences Rewiews.

Romnée, A., Evrard, A. and Trachte, S., 2015. Methodology for a stormwater sensitive urban watershed design. Journal of Hydrology, 530, 87-102.

Tiware, K., Roshan, M.B. and Bishal, K.S., 2008. Natural resource and watershed management in south Asia: a comparative evaluation with special references to Nepal. J. Agric. Environ., 9.

URL-1: https://www.epa.gov/watershedacademy. 25 Temmuz 2017.

Zare, M., Panagopoulos, T. and Loures, L., 2017. Simulating the impacts of future land use change on soil erosion in the Kasilian watershed, Iran. Land Use Policy, 67, 558-572. 